\title{
Modeling Multiple Interacting Nutrient Stocks: Application to the Baltic Sea
}

\author{
Natalia Kuosmanen ${ }^{1}$, Timo Kuosmanen ${ }^{2}$
}

\begin{abstract}
Eutrophication of water bodies is a worldwide ecological problem caused by excessive amounts of nutrients. This paper develops an accounting method for modeling multiple interacting stocks of nutrients, which applies the dynamic nutrient balance approach to calculate empirical nutrient budgets. The proposed model of multiple interacting stocks draws an explicit connection between nutrient stocks on land and nutrient stocks in the sea, which in turn links estimated marine nutrient stocks with the empirical data of nutrient concentrations. The model is applied to the Baltic Sea, where stocks of nitrogen and phosphorus are calculated for six basins, drawing distinction between surface, middle and deep water layers of the basins, and taking into account spatial interactions of nutrients within the water layers and between the basins. The model is calibrated using empirical data on nutrient loads and concentrations. Finally, we apply the model to forecast future development of nitrogen and phosphorus concentrations under different abatement scenarios.
\end{abstract}

Keywords: Dynamic Nutrient Model; Multiple Interacting Stocks; Nitrogen; Phosphorus; Eutrophication; Baltic Sea

\section{Introduction}

Eutrophication of water bodies such as sea coasts, lakes, and rivers is a worldwide environmental problem (e.g., Ryther and Dunstan, 1971; Vollenweider, 1971). The Baltic Sea is particularly vulnerable to eutrophication due to its delicate mixture of salt water from the North East Atlantic and fresh water from surrounding rivers and streams, which gives rise to a highly sensitive and interdependent marine ecosystem with unique flora and fauna (see, e.g., Voipio, 1981; Larsson et al., 1985; Wulff et al., 2001a). The enrichment of seawaters with nutrients leads to an accelerated growth of algae and higher forms of plant life. The two essential nutrients causing eutrophication of the Baltic Sea are compounds of nitrogen and phosphorus. Nitrogen occurs in various forms including nitrate, ammonium, and bioavailable organic nitrogen, and phosphorus is in the form of phosphate and bioavailable organic phosphorus.

Management of the Baltic Sea eutrophication is challenging due to complexity of the ecological system, involvement of multiple actors in the nutrient abatement efforts, as well as societal differences of countries in the region (e.g., HELCOM 2009, 2014, 2017). The first step towards addressing the problem is to understand the dynamics of the nutrient flows and stocks. There is a large and growing literature on eutrophication of the Baltic Sea, which can be divided into three broad streams: 1) direct measurement, 2) simulation models, and 3) empirical nutrient budgets.

The first stream of literature relies on direct measurement of nutrient loads and concentrations, qualitative and quantitative indicators of eutrophication, as well as

| ${ }^{1}$ Natural Resources Institute Finland (Luke), Helsinki, Finland

${ }^{2}$ Aalto University School of Business, Helsinki, Finland 
metrics that combine those indicators (e.g., HELCOM 2006, 2009, 2015; Andersen et al., 2006, 2011, 2017; Ærtebjerg et al., 2003). The standard approach to estimate amounts of nutrients in the Baltic Sea is to measure concentrations of nitrogen and phosphorus compounds from samples of seawater collected at different measuring stations during the winter season. Other commonly used indicators include chemical and biological measurements of water quality, such as water transparency, chlorophyll a concentrations, phytoplankton and oxygen concentration, among others. The HELCOM Eutrophication Assessment Tool (HEAT) is an example of a multi-metric indicator-based approach specifically developed to assess the eutrophication status in coastal as well as open see waters of the Baltic Sea (Andersen et al., 2011; HELCOM, 2014).

While direct measurement is clearly important, there are several challenges worth noting. The measured nutrient concentrations are known to be sensitive to the season, water depth, and distance to the coast (e.g., Rahm and Danielsson, 2007). This is also evident from empirical data that has large temporal and spatial fluctuations and wide confidence intervals (e.g., HELCOM, 2009; Wasmund et al., 2001; Hänninen and Vuorinen, 2015). The eutrophying nutrients are available in various chemical compounds that occur in relatively low concentrations (between 5 to 40 micromoles per liter), and are not uniformly mixed in the seawater. Further, the reported measurements of nutrient concentrations are usually from the water samples taken at the depth of 0-10 meters in the surface water layer. It is more difficult to measure nutrient concentrations in middle and deep water layers.

To address the difficulties in the direct measurement, the second stream of literature builds elaborate micro-level simulation models in order to analyze the ecological status of the Baltic Sea (e.g., Eilola et al., 2009, 2011; Savchuk and Wulff, 2007, 2009; Gustafsson et al., 2012; Savchuk et al., 2012). The simulation models are also used as a tool to evaluate possible management options for reducing eutrophication (e.g., Ahlvik and Pavlova, 2013; Ahlvik et al., 2014; Ahlvik and Iho, 2016; Iho et al., 2017). The complexity of the ecological system makes detailed micro level modeling a challenging task, requiring the use of relatively large numbers of parameters and assumptions. High resolution simulation models that combine hydrogeological and biochemical information (see, e.g., Savchuk et al., 2012) are also computationally intensive. Savchuk et al. (2012) note that "with such models a simulation of the entire Baltic Sea over several decades still requires many days of computation even at supercomputer centers, which greatly hinders numerical experimentation needed for both model calibration and sensitivity analysis, including scenario responses."

To balance the advantages and disadvantages of direct measurements versus high resolution computer simulations, the third approach applies relatively simple macro-level models calibrated to match the data from direct measurements to calculate empirical nutrient budgets. Wulff et al. (2001b), Savchuk (2005), and Savchuk and Wulff (2007) were among the first to evaluate the nitrogen and phosphorus budgets in different basins of the Baltic Sea and investigate their dependence on the nutrient inputs. These studies aptly reveal the high interconnectivity of the Baltic Sea basins as well as the slow and relatively weak responses of the Baltic Sea trophic state to reductions of the nutrient loads. Savchuk (2005) aptly summarizes the advantages of this approach as follows: "the empirical budgets, based on actual measurement, will remain a powerful tool both to derive overall system properties from the data and to verify theoretical budgets constructed from simulations." However, the 
empirical nutrient budgets published thus far build upon the general mass balance model assuming a linear system at a steady state. The model focuses on the nutrient flows, but ignores the accumulation of nutrient stocks over time. Thus, these models cannot forecast the dynamics of the nutrient stocks and concentrations, or how the effects would be distributed over time in the interconnected basins (Savchuk, 2005).

This paper proposes an alternative approach to calculate the empirical nutrient budgets based on the dynamic nutrient balance approach developed in Kuosmanen and Kuosmanen (2013). Making use of the country level nitrogen and phosphorus stocks in agricultural land (Kuosmanen, 2014), we model the flow of nutrients to six basins of the Baltic Sea: Baltic Proper, Gulf of Finland, Gulf of Riga, Bothnian Sea, Bothnian Bay, Danish Straits and Kattegat. Drawing a distinction between surface, middle, and bottomwater layers, we account for nutrient accumulation in each basin and compartment using the dynamic nutrient balance model with multiple stocks. Following Håkanson and Bryhn (2008), we utilize data of water fluxes between the basins to model the interactions of nutrient stocks between and within the basins by separating compartments of each basin into different water layers.

We believe the dynamic nutrient balance approach can offer insights and information beyond the direct measurements, micro-level simulation models, and empirical nutrient budgets. Firstly, the dynamic nutrient balance accounting of interacting stocks builds a natural connection between nutrient stocks on the land and nutrient stocks in the sea via nutrient run-offs from agricultural land. Secondly, this approach provides a dynamic framework for analyzing the development of nutrient stocks in different basins and different water layers over time. The dynamic model can also be used for forecasting the development of nutrient stocks over time under alternative policy scenarios. Thirdly, data from direct measurements can be used for calibrating the model parameters in the dynamic material balance model, which allows us to compare and contrast the empirical evidence from the direct measurements, simulations as well as nutrient budget approaches. Therefore, we see the dynamic nutrient balance approach considered in this paper not as a competitor but as a complement to the existing toolbox.

The rest of the paper is organized as follows. Section 2 presents the theoretical framework for the dynamic model of multiple interacting nutrient stocks. Section 3 describes the empirical application to the Baltic Sea and its basins and compartments. Section 4 presents the results and insights gained through the dynamic nutrient balance approach. Section 5 applies the dynamic nutrient balance model to forecast the development of nutrient stocks under alternative policy scenarios. Section 6 summarizes our findings and draws the concluding remarks. More detailed results for each basin and compartment of the Baltic Sea are provided in Appendices 1 and 2 (available as online supplement).

\section{Modeling Nutrient Stocks}

\subsection{Modeling Multiple Nutrient Stocks with Interactions}

Nitrogen and phosphorus can be naturally found as compounds in various forms in the seawater. Regardless of the chemical form, nutrients such as nitrogen and phosphorus exist in the sea at any given point of time, forming the total nutrient stock. 
Nitrogen and phosphorus can cycle within aquatic community by changing its molecular form by being locked in biomass, for example, when aquatic plants or fish obtain these nutrients from the sediment and seawaters, and then again release these elements.

This section introduces a simple discrete time model for multiple interacting stocks based on the dynamic nutrient balance approach (Kuosmanen and Kuosmanen, 2013). Similar to empirical nutrient budget studies (e.g., Savchuk, 2005; Savchuk and Wulff, 2007), the sea is divided into homogenous basins and compartments, which refer to a water layer in a basin of the sea (e.g., deep, middle and surface water layers). The basins and the compartments of the Baltic Sea will be introduced and discussed in more detail in Section 3.

The compartments are indexed as $i=1, \ldots, K$ and the time periods as $t=1, \ldots, T$. The stock of nutrient in compartment $i$ period $t$ is denoted by $Z_{i t}$. The stock is governed by the following discrete time dynamic nutrient balance equation:

$$
Z_{i t}=\left(1-\delta_{i}\right) Z_{i, t-1}-\sum_{\substack{j=1 \\ j \neq i}}^{K} \rho_{i j} Z_{i, t-1}+\sum_{\substack{j=1 \\ j \neq i}}^{K} \rho_{j i} Z_{j, t-1}+z_{i t}
$$

In equation (1), parameter ${ }^{\delta_{i}}$ represents decay of the stock, which occurs through various ecological processes such as sedimentation and air-sea gas exchange. Parameters $\rho_{i j}$ are the interaction terms that indicate the proportion of the nutrient stock in compartment $i$ that flows into compartment $j$ through water circulation and settling of nutrients from the surface towards the bottom compartments. The last parameter $z_{i t}$ indicates the net inflow of nutrient in compartment $i$. In the context of the Baltic Sea, the major nutrient inflows include losses of nutrients from diffuse sources, such as nitrogen and phosphorus run-offs from agricultural land; nutrient discharges from point sources, such as waste water treatment plants and industries; and atmospheric deposition of nitrogen and phosphorus to surface waters caused by air pollution.

Equation (1) is more elegantly restated using the notation of matrix algebra. Let vector $\mathbf{Z}_{t}=\left(Z_{1 t}, Z_{2 t}, \ldots, Z_{K t}\right)$ denote the stocks of nutrients in all compartments in period $t$, and similarly, denote the net inflows of nutrients to all compartments by vector $\mathbf{z}_{t}=\left(z_{1 t}, z_{2 t}, \ldots, z_{K t}\right)$. Using this notation, the dynamic discrete-time model of $K$ interacting stocks can be stated as

$$
\mathbf{Z}_{t}=\Delta \mathbf{Z}_{t-1}+\mathbf{z}_{t}
$$

where the square matrix $\Delta$ contains the model parameters:

$$
\boldsymbol{\Delta}=\left(\begin{array}{cccc}
1-\delta_{1} & \rho_{12} & \cdots & \rho_{1 K} \\
\rho_{21} & 1-\delta_{2} & \cdots & \rho_{2 K} \\
\vdots & \vdots & \ddots & \vdots \\
\rho_{K 1} & \rho_{K 2} & \cdots & 1-\delta_{K}
\end{array}\right) .
$$

Parameters $\delta_{i}$ in the diagonal of $\boldsymbol{\Delta}$ are the decay rates of stocks $i=1, \ldots, K$. The offdiagonal elements $\rho_{j i}$ determine the interactions between the stocks, as discussed above. Note that in general $\rho_{j i} \neq \rho_{i j}$, and therefore, matrix $\Delta$ is generally not symmetric.

To calculate the nutrient stocks in period $t$ using equation (2), the following information is needed: 1) the parameter values to construct matrix $\boldsymbol{\Delta}, 2)$ data of nutrient inflows $\mathbf{z}_{t}$, 
and 3) the starting values of the stocks $\mathbf{z}_{0}$ in period 0 . We discuss in detail how the model can be calibrated and applied to the case of the nitrogen and phosphorus stocks in the Baltic Sea in the next section.

Equation (3) implicitly assumes that the elements of matrix $\Delta$ are constant over time, but

differ across compartments. The interaction parameters $\rho_{i j}$ are the key drivers of the model. It seems natural to assume that a constant proportion of a nutrient stock is exchange with the neighboring stocks through water cycle and settling processes. The fact that the decay rates $\delta_{i}$ can differ across compartments allows us to model nonlinearities in the decay function (for example, Ahlvik et al., 2014, assume quadratic decay functions for nitrogen and phosphorus) as well as interdependence between nitrogen and phosphorus decay functions (cf. e.g., Boeykens et al., 2017). Since the stocks of nutrients are relatively stable over time, for analytical convenience, we assume that the decay rates $\delta_{i}$ are approximately constant over time. Note that the volume of decay does adjust to possible changes in the stocks of nutrients over time. Moreover, note that the assumption of constant $\boldsymbol{\Delta}$ over time can be easily relaxed by introducing parameters $\boldsymbol{\Delta}_{t}, t=1, \ldots, T$, that change over time, but in that case, one would need to make additional assumptions to be able to estimate the parameter values from empirical data (there is no free lunch).

In the present context, we see the simplicity and the minimal information needs as advantages of the proposed dynamic material balance framework. The development of the nutrient stock can be calculated without a need to resort to optimization, estimation or simulation. The parameter values in matrix $\Delta$ can be calibrated to match the available empirical data from direct measurements. The nutrient inflows ${ }^{\mathbf{z}_{t}}$ can also be based on the direct measurements, or outflows from the land-based nutrient stocks as in this study. Finally, the starting values $\mathbf{z}_{0}$ can be estimated using the perpetual inventory method, as described in Kuosmanen and Kuosmanen (2013). The stock equations are based on a simple accounting identity, and hence do not assume the system to be in a steady-state equilibrium, in contrast to Savchuk (2005) and Savchuk and Wulff (2007). Finally, the dynamic material balance can also be used for forecasting the development of nutrient stocks and concentrations in the future based on some plausible scenarios concerning the development of nutrient inflows $\mathbf{z}_{t}$, for example, under alternative policy scenarios for nutrient abatement.

\subsection{Linking Nutrient Stocks to Concentrations and Flows}

The long term average concentration of nutrients in the seawater can be derived from the estimated nutrient stock as:

$$
C_{i t}=Z_{i t} / V_{i}
$$

where $C_{i t}$ is the average concentration of nutrient in compartment $i$ in period $t$ ( $\mu$ mol per liter), $Z_{i t}$ is the total stock of nutrient in compartment $i$ in period $t$ (tons), and $V_{i}$ is the total volume of water in compartment $i$ (taken here as a time-invariant constant).

Equation (4) shows that, on average in the long run, the direct measurement of concentrations in water samples, averaged over large number of samples collected over time, must yield exactly the same result as the nutrient stock accounted at the macro 
level, divided by the water volume to obtain the average concentration. In the empirical application of this study (Section 4), we make use of this this mathematical fact to calibrate the parameter matrix $\boldsymbol{\Delta}$ such that the average surface concentrations of nutrients reported by HELCOM (2009) match as closely as possible with the concentrations derived from the estimated nutrient stocks obtained by the multiple interacting nutrient stocks model.

The dynamic nutrient balance model also helps to clarify the association between nutrient loads and concentrations. Clearly, the nutrient flow zit in compartment $i$ during period $t$ does indeed affect the concentration $C_{i t}$. Specifically, combining equations (1) and (4), we find that the marginal effect of the nutrient input $z_{i t}$ is

$$
d C_{i t} / d z_{i t}=\left(1 / V_{i}\right) \cdot d Z_{i t} / d z_{i t}=1 / V_{i} .
$$

Equation (5) shows that the marginal effect of the input zit is positive, but extremely small because the volume of the basin $V_{i}$ is generally very large.

Several empirical studies apply correlation and regression analysis to examine the statistical association of nutrient inputs and nutrient concentrations using time series data (see, e.g., HELCOM, 2009; Box 1, p. 21). If one regresses time series of nutrient concentrations $C_{i t}$ on inflows $z_{i t}$ using linear regression and data from the Baltic Sea, one will find a good empirical fit and much larger coefficients than $1 / V_{i}$. For example, HELCOM (2009; Box 1, p. 21) report the coefficients of determination $\left(R^{2}\right)$ as high as 0.63 for the dissolved inorganic nitrogen (DIN) concentration and 0.55 for the total nitrogen (TN) concentration in the open waters in the Kattegat and Danish Straits. We suspect that such high empirical correlation between the nutrient load and concentration is likely due to the fact that the time series of nutrient concentrations $C_{i t}$ and net inflows of nutrients $z_{i t}$ both have a decreasing trend over time, and the linear regression simply captures that time trend. Such a misleading statistical association is known as "spurious regression" in econometrics (e.g. Granger and Newbold, 1974, 1977; Phillips, 1986), and it is a common problem in time series data.

It is worth to emphasize that the problem of spurious regression in time series data of nutrient loads and concentrations is not only of concern in empirical studies; the calibration of parameters in simulation models is often based on regression analysis (e.g., Ahlvik et al., 2014). We hope that the explicit links between the stocks, flows and concentrations established in equations (1) - (5) and drawing attention to the problem of spurious regression might help to reduce the temptation to just casually regress time series data on nutrients without careful attention to modeling the time trends. As noted above, the dynamic nutrient balance approach considered in this paper avoids this problem as the parameter values $\Delta$ are calibrated based on estimates of water exchanges between basins and compartments such that the nutrient stocks correspond to the average nutrient concentrations observed in direct measurements from water samples through equation (4).

\section{Modeling Nutrient Stock in the Baltic Sea}

\subsection{Study Area}

In order to model interacting stocks of nitrogen and phosphorus in the Baltic 
Sea, we first divide the water area into the following basins: Baltic Proper (BP), Gulf of Finland (GF), Gulf of Riga (GR), Bothnian Sea (BS), Bothnian Bay (BB), and Danish Straits and Kattegat (DS+KT), as shown in Figure 1. We then follow the studies by Savchuk (2005), Håkanson and Lindgren (2010) and subdivide the basins into three compartments: the surface-water layer (SW), middle-water layer (MW) and deep-water layer (DW). The compartments' physical characteristics including depths of the basins and the surface area are presented in Table 1.

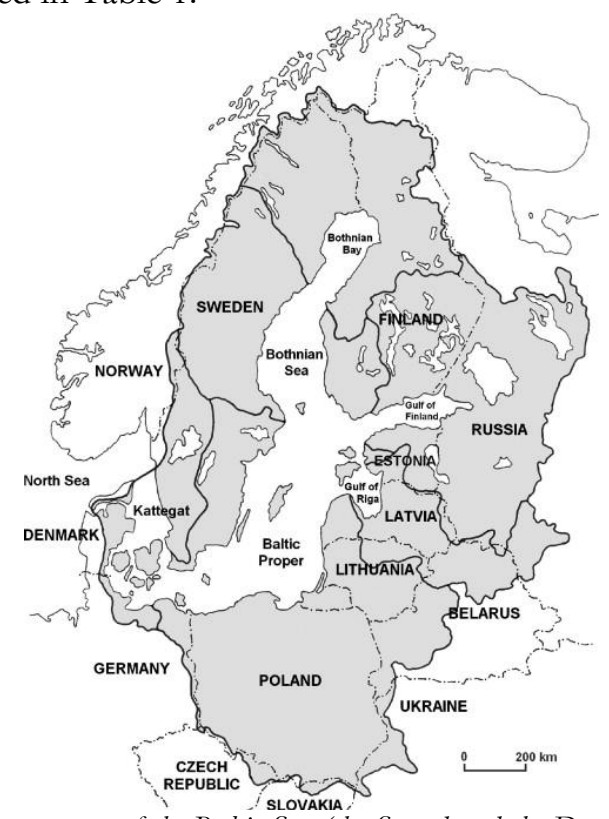

Figure 1. Basins and catchment areas of the Baltic Sea (the Sound and the Danish Belt Sea are included as the southern part of the Kattegat catchment area). Source: Larsen (2008).

As can be seen from Table 1, the basins of the Baltic Sea differ substantially in their physical characteristics, such as size, volume and depth. The water volumes are reported at the basin level; the water volumes of the compartments were estimated based on the surface area, the depth levels, and the bottom topography maps of the Baltic Sea and its basins. In this study, the Baltic Proper and the Gulf of Finland include three compartments: surface, middle and deep water layers; the Bothnian Sea, the Bothnian Bay and the Gulf of Riga include surface and deep water layers; and the Danish Straits plus Kattegat include only one compartment - the surface water layer. The surface water layer is considered to be up to 44 meters deep, the middle water layer is between 44 and 75 meters (except for the Bothnian Sea), and the deep water layer takes up to 105 meters for the Gulf of Finland and 459 for the Baltic Proper. Regarding the Bothnian Sea, even though its depth is 301 meters, we prefer to model it as a basin with two compartments - the surface and deep water layers in line with the calculations of water exchange between the basins as in the study of Håkanson and Lindgren (2010).

Table 2 reports the values of the parameter matrix $\Delta$ used in this study. The decay rates $\delta_{i}$ were calibrated to match the direct measurements of nutrient concentrations reported 
by Helsinki Commission (HELCOM). ${ }^{1}$ We set the decay rate of nitrogen as $3 \%$ for all basins and compartments. The decay rate of phosphorus is set at $0.1 \%$ for all basins and compartments, except for the Gulf of Riga and Bothnian Bay. Note that the decay rates are small in comparison to interactions with other compartments through water exchange.

Table 1. Physical characteristics of the basins.

\begin{tabular}{l|c|c|c|c}
\hline Basin - Compartment & Abbreviation & Area, km & Volume, $\mathbf{k m}^{\mathbf{3}}$ & Depth, $\mathbf{m}$ \\
\hline Baltic Proper - Surface Water & BP_SW & 211069 & 8622 & $0-43$ \\
Baltic Proper - Middle Water & BP_MW & - & 3622 & $43-75$ \\
Baltic Proper - Deep Water & BP_DW & - & 801 & $75-459$ \\
\hline Gulf of Finland - Surface Water & GF_SW & 29600 & 823 & $0-43.8$ \\
Gulf of Finland - Middle Water & GF_MW & - & 203 & $43.8-75$ \\
Gulf of Finland - Deep Water & GF_DW & - & 74 & $75-105$ \\
\hline Gulf of Riga - Surface Water & GR_SW & 16300 & 320 & $0-39.2$ \\
Gulf of Riga - Deep Water & GR_DW & - & 105 & $39.2-56$ \\
\hline Bothnian Sea - Surface Water & BS_SW & 79000 & 3022 & $0-42.5$ \\
Bothnian Sea - Deep Water & BS_DW & - & 1348 & $42.5-301$ \\
\hline Bothnian Bay - Surface Water & BB_SW & 36800 & 1059 & $0-41.4$ \\
Bothnian Bay - Deep Water & BB_DW & - & 977 & $41.4-56$ \\
\hline Danish Straits and Kattegat & DS+KT & 42408 & 1422 & $0-109$ \\
\hline
\end{tabular}

Table 2. Parameter matrix $\Delta$. Diagonal elements represent one minus the decay rate of the nitrogen stocks (phosphorus in parenthesis) and the off-diagonal elements are the portion of stock exchanged with adjacent basins and within the layers.

\begin{tabular}{|c|c|c|c|c|c|c|c|c|c|c|c|c|c|}
\hline & \multicolumn{3}{|c|}{ Baltic Proper } & \multicolumn{3}{|c|}{ Gulf of Finland } & \multicolumn{2}{|c|}{ Gulf of Riga } & \multicolumn{2}{|c|}{ Bothnian Sea } & \multicolumn{2}{|c|}{ Bothian Bay } & \multirow{2}{*}{$\begin{array}{l}\text { DS } \\
+\mathrm{KT}\end{array}$} \\
\hline & SW & MW & DW & SW & MW & DW & SW & DW & SW & DW & SW & DW & \\
\hline BP_SW & $\begin{array}{l}0.970 \\
(0.999)\end{array}$ & 0.029 & 0 & 0.285 & 0 & 0 & 0.100 & 0 & 0.087 & 0 & 0 & 0 & 0.045 \\
\hline BP_MW & 0.011 & $\begin{array}{l}0.970 \\
(0.999)\end{array}$ & 0.046 & 0 & 0.103 & 0 & 0 & 0.146 & 0 & 0 & 0 & 0 & 0.010 \\
\hline BP_DW & 0 & 0.008 & $\begin{array}{l}0.970 \\
(0.999)\end{array}$ & 0 & 0 & 0.285 & 0 & 0 & 0 & 0 & 0 & 0 & 0.006 \\
\hline GF_SW & 0.024 & 0 & 0 & $\begin{array}{l}0.970 \\
(0.999)\end{array}$ & 0.285 & 0 & 0 & 0 & 0 & 0 & 0 & 0 & 0 \\
\hline GF_MW & 0 & 0.006 & 0 & 0.070 & $\begin{array}{l}0.970 \\
(0.999)\end{array}$ & 0.034 & 0 & 0 & 0 & 0 & 0 & 0 & 0 \\
\hline GF_DW & 0 & 0 & 0.026 & 0 & 0.012 & $\begin{array}{l}0.970 \\
(0.999)\end{array}$ & 0 & 0 & 0 & 0 & 0 & 0 & 0 \\
\hline GR_SW & 0.003 & 0 & 0 & 0 & 0 & 0 & $\begin{array}{l}0.970 \\
(0.700)\end{array}$ & 0.141 & 0 & 0 & 0 & 0 & 0 \\
\hline GR_DW & 0 & 0.004 & 0 & 0 & 0 & 0 & 0.046 & $\begin{array}{l}0.970 \\
(0.700)\end{array}$ & 0 & 0 & 0 & 0 & 0 \\
\hline BS_SW & 0.022 & 0 & 0 & 0 & 0 & 0 & 0 & 0 & $\begin{array}{l}0.970 \\
(0.999)\end{array}$ & 0.058 & 0.072 & 0 & 0 \\
\hline BS_DW & 0 & 0.003 & 0 & 0 & 0 & 0 & 0 & 0 & 0.023 & $\begin{array}{l}0.970 \\
(0.999) \\
\end{array}$ & 0 & 0 & 0 \\
\hline BB_SW & 0 & 0 & 0 & 0 & 0 & 0 & 0 & 0 & 0.014 & 0 & $\begin{array}{l}0.970 \\
(0.850)\end{array}$ & 0.167 & 0 \\
\hline BB_DW & 0 & 0 & 0 & 0 & 0 & 0 & 0 & 0 & 0 & 0.003 & 0.150 & $\begin{array}{l}0.970 \\
(0.850)\end{array}$ & 0 \\
\hline $\mathbf{D S}+\mathrm{KT}$ & 0.026 & 0 & 0 & 0 & 0 & 0 & 0 & 0 & 0 & 0 & 0 & 0 & $\begin{array}{l}0.970 \\
(0.999) \\
\end{array}$ \\
\hline
\end{tabular}

The interaction terms ${ }^{\rho_{j i}}$ were calibrated based on the estimates of annual water fluxes for the Baltic Sea presented in Håkanson and Bryhn (2008) and Håkanson and Lindgren (2010), assuming the total volume of water in each basin remains constant. Obviously, water is exchanged only with the adjacent basins; the zero values of parameters $\rho_{j i}$ mean

${ }^{1}$ HELCOM: http://www.helcom.fi/helcom-at-work/projects/completed-projects/plc-5-5/ 
that no water exchange occurs between the compartments. For example, consider the Danish Straits and Kattegat where 2.6 percent of nutrients mixed with water are moving annually to surface waters of the Baltic Proper and join the stock of nutrients present in this compartment. Further, 28.5 percent of the surface waters of Baltic Proper join the nutrient stock present in the surface water layer of the Gulf of Finland, and 10.3 percent of water with mixed in it nutrients moves annually from middle water layer of Baltic Proper to the middle water layer of the Gulf of Finland.

\subsection{Nutrient Inputs to the Baltic Sea}

In order to estimate nutrient stocks in the Baltic Sea and its basins, we need the following information about nutrients' flows. Firstly, we need to know how much nutrients enter each basin annually. The main inflows of nitrogen and phosphorus that influence the total amount of nutrient stocks in the Baltic Sea are: nutrient run-offs from diffuse sources, such as agriculture, managed forestry and scattered dwellings; nutrient discharges from point sources, such as waste water treatment plants, industries and aquaculture; and atmospheric deposition of nutrients to the sea due to air pollution in this region. The data on discharges of nutrients from point sources and atmospheric deposition to the Baltic Sea are readily available from HELCOM for the years 19942010 (see footnote 1). However, estimation of nutrient run-offs from agriculture is not as straightforward, as discussed in the following sub-section.

Secondly, we need information about the exchange of nutrients between and within the basins, which was discussed in the previous sub-section. Thirdly, to estimate nutrient stocks we need information about the major nutrient outflows from the stocks. Those include the permanent sediment burial, denitrification, and export to the Skagerrak and North Sea. All these flows of nutrients are also taken into account in the calibration of parameter matrix $\boldsymbol{\Delta}$ (see Table 2).

\subsubsection{Nutrient Run-offs from Agricultural Land}

As has been mentioned above, nutrient run-offs from agricultural land are the largest source of nitrogen and phosphorus enrichment in the Baltic Sea region. In order to estimate nutrient losses from agriculture, we apply the dynamic nutrient balance approach developed in Kuosmanen and Kuosmanen (2013). For the purposes of our application of nutrient stocks estimation in the Baltic Sea, we assess agricultural stocks and run-offs of nitrogen and phosphorus in the following countries: Finland, Germany, Sweden, Denmark, Estonia, Latvia, Lithuania, Poland and Russia.

Following Kuosmanen (2014), we use readily available data of gross nutrient balances obtained from the Eurostat statistical databases ${ }^{2}$ and construct agricultural stocks for each country under analysis. Eurostat's gross nutrient balances represent a measure, which is calculated as total nutrient inputs minus total nutrient outputs and expressed in tons of nutrient per year. Further, to estimate nutrient run-offs from agriculture to the basins of the Baltic Sea, we apply the riverine monitoring data from HELCOM to the estimated agricultural stocks of nitrogen and phosphorus in order to calibrate the leaching rates. The purpose is to estimate the portion of the total agricultural run-off in

${ }^{2}$ EUROSTAT: http://ec.europa.eu/eurostat/data/database 
each country specifically to the Baltic Sea basins.

The HELCOM data of riverine loads of nitrogen and phosphorus are typically used as measures of agricultural run-offs of nutrients and nutrient loading in the Baltic Sea. However, the monitoring data are based on direct measurement of nutrient concentration in water samples in different monitored and unmonitored areas, and hence the results show unrealistically high fluctuations from one year and another. Applying the dynamic nutrient stock model provides more stable estimates of nutrient discharges from the diffuse sources, such as agriculture.

For the nitrogen stocks in Finland, Germany, Sweden and Denmark, we use the estimates reported in Kuosmanen (2014). For other countries we calculate the agricultural stocks and run-offs of nitrogen utilizing the Eurostat's gross nutrient balance data and the HELCOM riverine data. However, since gross nutrient balance data are unavailable for Russia, we use the HELCOM data for this country, calibrated with the help of the dynamic nutrient model. Below we present some illustrative results for the selected countries.

Run-off of total nitrogen and phosphorus from agricultural activities in Sweden are depicted in Figures 2 and 3, respectively. The broken line indicates the monitoring riverine data of HELCOM and the solid line is agricultural run-off of total nitrogen and phosphorus estimated by the dynamic nutrient balance model.

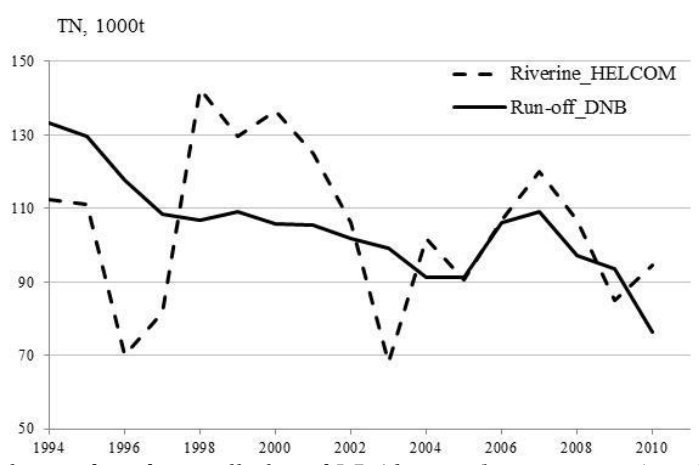

Figure 2. Development of agricultural run-off of total $N$ (thousand tons per year) in Sweden; the broken line is the HELCOM riverine and the solid line is the estimated agricultural run-off.

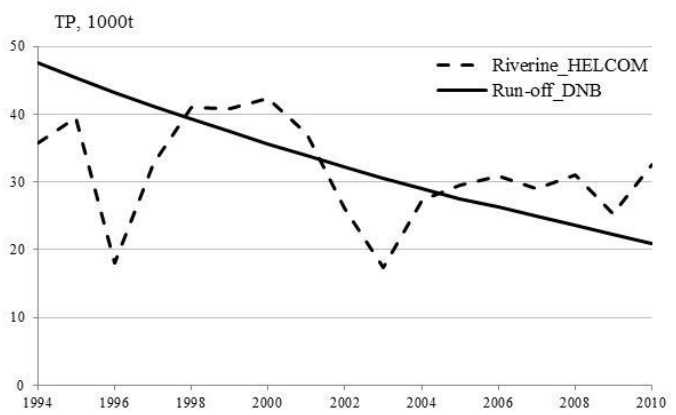

Figure 3. Development of agricultural run-off of total P (thousand tons per year) in Sweden; the broken line is the HELCOM riverine and the solid line is the estimated agricultural run-off. 
As can be seen from Figures 2 and 3, the estimated nutrient run-offs for both nitrogen and phosphorus is much smoother compared to the riverine data of HELCOM. This is due to the fact that the HELCOM data is based on the direct measurements of nutrient concentrations in water samples in discrete points of time. For other countries of the Baltic Sea region, a similar comparison of the development of total nitrogen and phosphorus run-offs from agriculture compared to the riverine data of HELCOM can be found in the Appendix 1.

\subsubsection{Eutrophication, Forms of Nutrients and Summary Statistics of Total Inputs}

Dissolved inorganic nitrogen (DIN) and dissolved inorganic phosphorus (DIP) are the forms of nitrogen and phosphorus that are readily available to phytoplankton, and are hence particularly responsible for the formation of blooms. However, when phytoplankton blooms, DIN and DIP in surface water layers can be totally consumed. Therefore, these types of nutrients are usually measured in winter, when biological activity of plankton is at its lowest stage. Total nitrogen (TN) and total phosphorus (TP) include all forms of nitrogen and phosphorus, and are considered to be more robust measures, which can be assesses throughout the year.

We stress that application of the dynamic nutrient balance model is not limited to any specific form of nutrient. To be more specific, in this study we focus on dissolved nitrogen and phosphorus, that is, DIN and DIP. Estimated nutrient run-offs from agricultural activities, atmospheric deposition of nutrients and nutrient discharges from point sources are represented by TN and TP. To find a portion of DIN and DIP in TN and TP, we use the HELCOM data of winter means of inorganic nutrients in the surface layer and annual means of total nutrients in six basins of the sea. Table 3 presents summary statistics of the estimated inflows of DIN and DIP into the six basins of the Baltic Sea. As can be seen from this table, the Gulf of Riga is the main receiver of DIN, whereas the Gulf of Finland is the main receiver of DIP.

Table 3. Descriptive statistics of the inflow of DIN and DIP ( $\mathrm{t}$ per $\mathrm{km}^{3}$ measured quarterly).

\begin{tabular}{lcccccc}
\hline DIN & $\begin{array}{c}\text { Baltic } \\
\text { Proper }\end{array}$ & $\begin{array}{c}\text { Gulf of } \\
\text { Finland }\end{array}$ & $\begin{array}{c}\text { Gulf of } \\
\text { Riga }\end{array}$ & $\begin{array}{c}\text { Bothnian } \\
\text { Sea }\end{array}$ & $\begin{array}{c}\text { Bothnian } \\
\text { Bay }\end{array}$ & $\begin{array}{c}\text { Danish straits } \\
\text { and Kattegat }\end{array}$ \\
\hline Mean & 1.60 & 7.90 & 11.10 & 0.90 & 2.72 & 8.08 \\
Median & 1.52 & 7.79 & 11.16 & 0.90 & 2.67 & 7.59 \\
Std.Dev. & 0.15 & 0.34 & 0.37 & 0.11 & 0.36 & 1.17 \\
Min & 1.44 & 7.47 & 10.49 & 0.75 & 2.18 & 6.29 \\
Max & 1.93 & 8.49 & 11.65 & 1.09 & 3.31 & 10.26 \\
\hline DIP & & & & & & \\
\hline Mean & 0.21 & 1.66 & 1.26 & 0.13 & 0.13 & 0.50 \\
Median & 0.21 & 1.69 & 1.22 & 0.12 & 0.12 & 0.48 \\
Std.Dev. & 0.04 & 0.09 & 0.28 & 0.02 & 0.03 & 0.11 \\
Min & 0.09 & 1.46 & 0.84 & 0.09 & 0.09 & 0.36 \\
Max & 0.17 & 1.77 & 1.77 & 0.17 & 0.17 & 0.74 \\
\hline
\end{tabular}

\section{Results}

In this section we report the main results of the empirical study. Using nutrient 
inputs discussed in sub-section 3.2, we estimate interacting stocks of nitrogen and phosphorus in six basins of the Baltic Sea and their compartments using equation (2). We first present results on estimated nitrogen and phosphorus stocks in six basins of the Baltic Sea and their compartments, calculated quarterly in tonnes. We then present nitrogen and phosphorus concentration measures, which are derived from the estimated stocks using equation (4), reported in in $\mu \mathrm{mol}$ per liter to be consistent with the measurement data of HELCOM.

Table 4 reports values of nitrogen and phosphorus stocks in each basin of the Baltic Sea and their compartments (in 1,000 tonnes) during the period 1995-2010. According to our results, nitrogen and phosphorus stocks have decreased in all basins and their compartments. The largest decline occurred in nitrogen stocks in the Danish Straits and Kattegat. The smallest change in nitrogen stock took place in the Gulf of Riga. However, phosphorus stocks in the Gulf of Riga showed the most notable decrease.

Table 4. Development of nitrogen (DIN) and phosphorus (DIP) stocks by basin during 1995 2010 (1000 tonnes) and the mean annual percentage change (Ch. \%).

\begin{tabular}{lcccccc|ccccc|c}
\hline & \multicolumn{6}{c|}{ DIN } & \multicolumn{6}{c}{ DIP } \\
Basin & Layer & $\mathbf{1 9 9 5}$ & $\mathbf{2 0 0 0}$ & $\mathbf{2 0 0 5}$ & $\mathbf{2 0 1 0}$ & $\mathbf{C h .} \mathbf{0}$ & $\mathbf{1 9 9 5}$ & $\mathbf{2 0 0 0}$ & $\mathbf{2 0 0 5}$ & $\mathbf{2 0 1 0}$ & \multicolumn{1}{c}{ Ch.\% } \\
\hline Baltic Proper & SW & 608 & 587 & 547 & 523 & -0.93 & 61.37 & 56.08 & 48.42 & 41.80 & -2.13 \\
& MW & 140 & 134 & 128 & 120 & -0.92 & 46.73 & 37.44 & 31.96 & 27.67 & -2.72 \\
Gulf of Finland & DW & 20.4 & 19.5 & 18.4 & 17.3 & -1.07 & 31.65 & 30.66 & 27.29 & 23.82 & -1.65 \\
& SW & 71.8 & 69.7 & 65.6 & 63.1 & -0.78 & 12.34 & 11.73 & 11.09 & 9.69 & -1.43 \\
& MW & 13.7 & 13.4 & 12.7 & 12.1 & -0.78 & 2.56 & 2.46 & 2.16 & 1.86 & -1.83 \\
Gulf of Riga & DW & 2.0 & 1.9 & 1.8 & 1.7 & -1.01 & 4.26 & 4.20 & 4.01 & 3.71 & -0.86 \\
& SW & 43.2 & 42.9 & 40.9 & 39.7 & -0.54 & 8.32 & 7.69 & 6.67 & 5.66 & -2.13 \\
Bothnian Sea & DW & 8.2 & 8.0 & 7.7 & 7.4 & -0.63 & 2.26 & 1.87 & 1.61 & 1.41 & -2.52 \\
& SW & 167 & 163 & 150 & 140 & -1.10 & 22.64 & 21.26 & 18.51 & 15.83 & -2.01 \\
Bothnian Bay & DW & 49.3 & 47.2 & 44.9 & 41.6 & -1.04 & 10.83 & 10.96 & 10.63 & 9.98 & -0.52 \\
& SW & 72.3 & 69.7 & 62.9 & 56.5 & -1.45 & 3.67 & 3.47 & 3.03 & 2.61 & -1.93 \\
DS +KT & DW & 55.6 & 54.2 & 50.1 & 44.9 & -1.28 & 7.09 & 6.30 & 5.66 & 4.95 & -2.01 \\
& & 61.7 & 57.0 & 50.3 & 47.1 & -1.58 & 11.56 & 10.64 & 9.32 & 8.12 & -1.99 \\
\hline
\end{tabular}

We next convert the estimated stocks into concentration measures using equation (4). Table 5 reports the concentrations of nitrogen and phosphorus in each basin and each compartment in $\mu \mathrm{mol} \mathrm{1-1}$.

Table 5. Development of nitrogen (DIN) and phosphorus (DIP) concentrations by basin and compartment during $1995-2010\left(\mu \mathrm{mol} \mathrm{l}^{-1}\right)$.

\begin{tabular}{lccccc|cccc}
\hline \multirow{2}{*}{ Basin } & \multicolumn{4}{c|}{ DIN } & \multicolumn{4}{c}{ DIP } \\
\hline Baltic Proper & Layer & $\mathbf{1 9 9 5}$ & $\mathbf{2 0 0 0}$ & $\mathbf{2 0 0 5}$ & $\mathbf{2 0 1 0}$ & $\mathbf{1 9 9 5}$ & $\mathbf{2 0 0 0}$ & $\mathbf{2 0 0 5}$ & $\mathbf{2 0 1 0}$ \\
& SW & 5.03 & 4.86 & 4.53 & 4.33 & 0.23 & 0.21 & 0.18 & 0,16 \\
& MW & 2.75 & 2.65 & 2.51 & 2.37 & 0.42 & 0.33 & 0.28 & 0,25 \\
Gulf of Finland & DW & 1.84 & 1.74 & 1.64 & 1.54 & 1.28 & 1.24 & 1.10 & 0,96 \\
& SW & 6.19 & 6.04 & 5.69 & 5.47 & 0.48 & 0.46 & 0.44 & 0.38 \\
& MW & 4.81 & 4.70 & 4.45 & 4.24 & 0.41 & 0.39 & 0.34 & 0.30 \\
Gulf of Riga & DW & 1.99 & 1.89 & 1.79 & 1.69 & 1.87 & 1.84 & 1.76 & 1.63 \\
& SW & 9.65 & 9.60 & 9.15 & 8.86 & 0.84 & 0.78 & 0.67 & 0.57
\end{tabular}




\begin{tabular}{lccccc|cccc}
\hline \multirow{2}{*}{ Basin } & & \multicolumn{4}{c|}{ DIN } & \multicolumn{4}{c}{ DIP } \\
\hline \multirow{3}{*}{ Bothnian Sea } & Layer & $\mathbf{1 9 9 5}$ & $\mathbf{2 0 0 0}$ & $\mathbf{2 0 0 5}$ & $\mathbf{2 0 1 0}$ & $\mathbf{1 9 9 5}$ & $\mathbf{2 0 0 0}$ & $\mathbf{2 0 0 5}$ & $\mathbf{2 0 1 0}$ \\
& DW & 5.58 & 5.49 & 5.28 & 5.06 & 0.70 & 0.58 & 0.50 & 0.43 \\
Bothnian Bay & SW & 3.95 & 3.84 & 3.55 & 3.30 & 0.24 & 0.23 & 0.20 & 0.17 \\
& DW & 2.61 & 2.50 & 2.38 & 2.20 & 0.26 & 0.26 & 0.25 & 0.24 \\
DS +KT & SW & 4.87 & 4.70 & 4.24 & 3.81 & 0.11 & 0.11 & 0.09 & 0.08 \\
& DW & 4.06 & 3.96 & 3.66 & 3.29 & 0.23 & 0.21 & 0.19 & 0.16 \\
& & 3.10 & 2.86 & 2.52 & 2.36 & 0.26 & 0.24 & 0.21 & 0.18 \\
\hline
\end{tabular}

Similar to the results of nutrient stocks, the nitrogen concentrations have been gradually decreasing during the study period (Table 5). Interestingly, the nitrogen concentrations are highest in the surface water layers (SW) and decrease towards the middle (MW) and deep water (DW) layers. There are at least three explanations for this pattern. First, the nutrient inputs such as riverine inflow and atmospheric deposition enter the surface water layers first, and are subsequently transmitted to other layers through settling and water exchange. Second, nitrogen decay via sedimentation processes occurs in the bottom layers. Third, the inflow of salty water from Kattegat to the Baltic Proper occurs through the bottom layers. In our model, parameters vector $\Delta$ takes into account all these three effects.

Figures 4 and 5 display the development of dissolved inorganic nitrogen (DIN) and dissolved inorganic phosphorus (DIP) concentrations in the Gulf of Finland in years 1994 - 2005. The broken lines are the concentrations of DIN and DIP from the direct measurements reported by HELCOM. These concentrations are winter means in the surface waters (0-10 m) (HELCOM, 2009). The solid lines represent the concentrations of DIN and DIP estimated by the dynamic material balance approach. These measures are converted from the estimated stocks estimates of DIN and DIP from tonnes into $\mu \mathrm{mol}$ per liter. In contrast to HELCOM estimates, the concentrations obtained by the DNB method are calculated for the surface water layer of the Gulf of Finland (0-44 m).

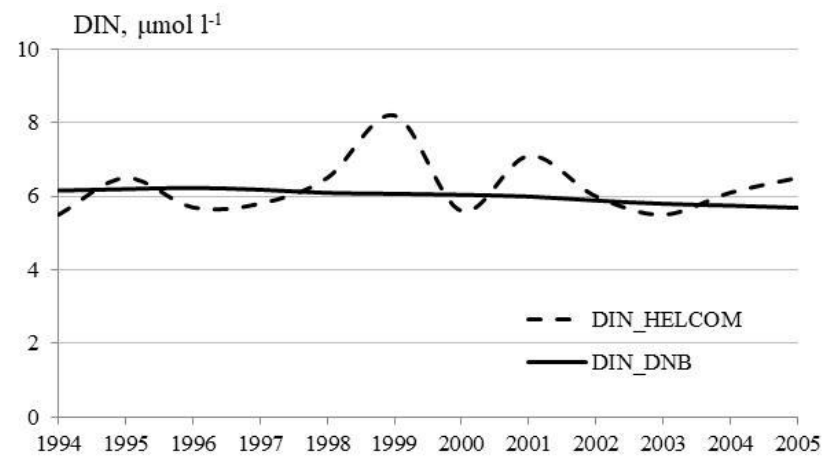

Figure 4. Development of DIN concentrations in the Gulf of Finland in 1994-2005 according to HELCOM and the proposed DNB method.

Figure 4 illustrates that the DIN concentration estimated by the dynamic material balance approach matches well the data from direct measurements based on samples of seawater. In the case of phosphorus (Figure 5), the DIP concentrations are of the similar 
magnitude, but the average concentrations derived from the phosphorus stock are notably lower than concentrations obtained from direct measurements. This can be at least partly explained by the fact that in our calculations the surface water layer in the Gulf of Finland is considered to be up to 40 meters deep, and the empirical samples of the HELCOM are taken only at depth of 10 meters or less. Comparing the results of both DIN and DIP, we see that average concentrations from the direct measurements are much more volatile than the results of the dynamic material balance approach. For other basins and compartments, similar figures depicting the developments of DIN and DIP concentrations are presented in Appendix 2.

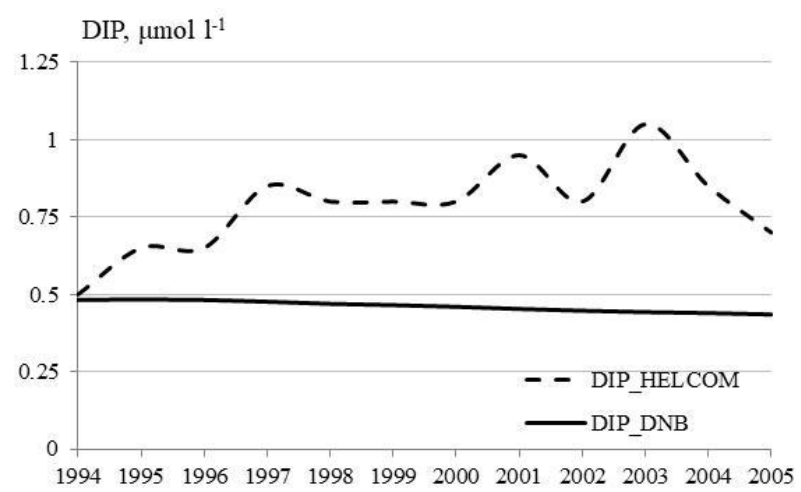

Figure 5. Development of DIP concentrations in the Gulf of Finland in 1994-2005 according to HELCOM and the proposed DNB method.

\section{Forecasting Future Nutrient Trends in the Baltic Sea}

We noted in Section 2 that the dynamic nutrient balance approach could be useful for forecasting the future development of nutrient stocks and concentrations under alternative policy scenarios. As an illustration, in this section we consider alternative scenarios for future development of nutrient abatement in the Baltic Sea area, and analyze how this will affect the stocks and the concentration levels of DIN and DIP. The three scenarios considered are the following:

1) Baseline: the current trend of nutrient reduction continues as is.

2) HELCOM: the targets of the Baltic Sea Action Plan are reached by 2021.

3) Reduction of agricultural run-offs by $20 \%$ (Scenario 3a) and $30 \%$ (Scenario 3b).

In the baseline scenario we simply assume that the same trend of nutrient reduction continues in the future. This would obviously require taking further abatement measures. In the second scenario, we adjust our model so that the maximum allowable inputs defined in the HELCOM Baltic Sea Action Plan (HELCOM, 2013) are reached by 2021. The maximum allowable inputs are predefined targets of water- and airborne nitrogen and phosphorus. According to HELCOM, despite the different amounts of reduction targets for different basins, annual phosphorus reduction can be reached even by implementing all possible measures, including the most stringent and expensive ones. In the third scenario we examine how nutrient stock and concentration levels change in response to a reduction of agricultural run-offs. Two sub-scenarios consider reducing the run-offs by 
20 percent (3a) and 30 percent (3b) relative to the current level, respectively. Scenario 3 is motivated by an ongoing large-scale pilot on gypsum application to agricultural fields is currently taking place in southwestern Finland. This pilot testes a new water protection method of applying gypsum to the agricultural soils (Ekholm et al., 2011; Uusitalo et al.., 2012; Iho and Laukkanen, 2012). This method suggests that gypsum can reduce the phosphorus load by half without requiring changes in farming practices or a decrease in cultivation area or yields (Jaakkola et al.., 2012; Ekholm et al., 2012).

The forecasted development of DIN and DIP concentrations during the period 1995 2050 in the surface layer of the Gulf of Finland are depicted in Figures 6 and 7.

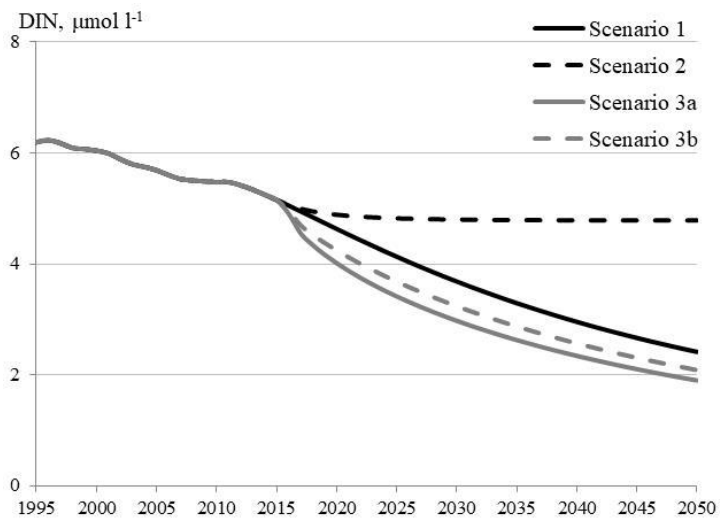

Figure 6. Development of DIN concentrations in the surface layer of the Gulf of Finland according to three forecasting scenarios.

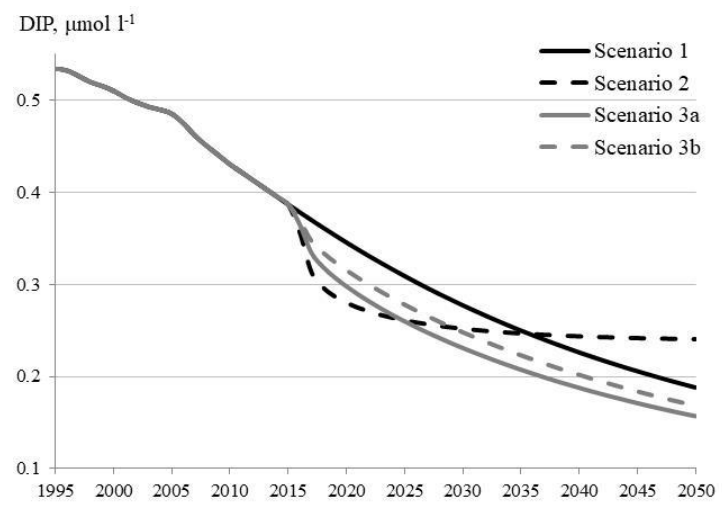

Figure 7. Development of DIP concentrations in the surface layer of the Gulf of Finland according to three forecasting scenarios.

In the baseline scenario the DIN and DIP concentrations continue the current downward trend, as expected. In the second scenario, reaching the HELCOM targets has little impact on the DIN concentration. This is because the HELCOM targets are already met in most regions: reaching lower DIN concentration would require more stringent targets and policy measures. The HELCOM scenario shows a quick effect on the DIP concentration, which then gradually levels off as the targets are reached. The 
different pattern of the DIN and DIP concentrations is due to the fact that the phosphorus cycle is much slower than that of nitrogen. Finally, Scenario 3 indicates that reduction of agricultural run-offs would likely be the most effective and cost efficient policy measure. Note that the impact of immediate reductions continues far into future because the dynamic material balance model takes into account the development of nutrient stocks in the agricultural lands. Reducing nutrient input to agricultural lands would gradually affect the run-offs to the Baltic Sea, and gradually affect the nutrient stocks accumulated in the seawater.

\section{Conclusions}

This paper considered an alternative approach to modeling empirical nutrient budgets using the dynamic nutrient balance approach with multiple interacting nutrient stocks. The flow of nutrients to six basins of the Baltic Sea was modeled using the country level nitrogen and phosphorus stocks in agricultural land, drawing a distinction between surface, middle, and bottom-water layers. The calibration of model parameters was based on available data of water fluxes between the basins and compartments and the average concentrations in the direct measurements from water samples.

We believe the macro-level dynamic nutrient balance approach provides insights beyond the direct measurements, high-resolution micro-level simulation models, as well as conventional empirical nutrient budgets. Firstly, the dynamic nutrient balance accounting of interacting stocks helps to build natural connections between nutrient stocks and concentrations, as well as nutrient stocks on the land and nutrient stocks in the sea. Secondly, this approach provides a simple macro-level accounting approach to analyzing the development of nutrient stocks in different basins and different water layers over time. The dynamic model can also be utilized to forecast the development of nutrient stocks over time under alternative policy scenarios. Thirdly, all model parameters of the dynamic material balance model can be calibrated to fit the average nutrient concentrations from direct measurements, which allows us to compare and contrast the empirical evidence from micro-level simulations as well as other nutrient budget approaches. Therefore, we see the dynamic nutrient balance approach considered in this paper not as a competitor but as a complement to the existing toolbox of eutrophication research.

The results of our empirical analysis confirmed that both nitrogen and phosphorus stocks declined in each basin of the Baltic Sea and all water layers over the last decade. Regarding nutrient concentrations of dissolved inorganic nitrogen and phosphorus, which we obtained from the estimated nutrient stocks, we discovered that our estimated nitrogen concentrations fit very well to the empirical measures of HELCOM's concentrations, which were obtained from water samples. However, the estimated phosphorus concentrations are generally smaller than the direct measurements suggest. The estimated nutrient concentrations are notably more stable over time than the direct measurements data. Finally, we conducted three forecasting scenarios to find out which of the reduction schemes would result in largest nutrient abatement. According to the results of our forecasting exercise, the largest reduction in both nitrogen and phosphorus would be reached by reducing agricultural run-offs of these nutrients. 


\section{References}

Ærtebjerg, G., Andersen, J.H., Hansen, O.S. (2003). Nutrients and eutrophication in Danish marine waters. A challenge for science and management. National Environmental Research Institute, $126 \mathrm{pp}$.

Ahlvik, L., Ekholm, P., Hyytiäinen, K., Pitkänen, H. (2014). An economic-ecological model to evaluate impacts of nutrient abatement in the Baltic Sea. Environmental Modelling and Software, 55, 164-175.

Ahlvik, L., Iho, A. (2016). Cost-benefit rules for geoengineering. Working paper, Natural Resource Institute Finland.

Ahlvik, L., Pavlova, Y. (2013). A strategic analysis of eutrophication abatement in the Baltic Sea. Environmental and Resource Economics, 56, 353-378.

Andersen, J.H., Axe, P., Backer, H., Carstensen, J., Claussen, U., Fleming-Lehtinen, V., Järvinen, M., Kaartokallio, H., Knuuttila, S., Korpinen, S., Laamanen, M., Lysiak-Pastuszak, E., Martin, G., Møhlenberg, F., Murray, C., Nausch, G., Norkko, A., Villnäs, A. (2011). Getting the measure of eutrophication in the Baltic Sea: towards improved assessment principles and methods. Biogeochemistry, 106, 137-156.

Andersen, J.H., Carstensen, J., Conley, D.J., Dromph, K., Fleming- Lehtinen, V., Gustafsson, B.G., Josefson, A.B., Norkko, A., Villnäs, A., Murray, C. (2017). Long- term temporal and spatial trends in eutrophication status of the Baltic Sea. Biological Reviens, 92, 136-149.

Andersen, J.H., Schlüter, L., Ærtebjerg, G. (2006). Coastal eutrophication: recent developments in definitions and implications for monitoring strategies. Journal of Plankton Research, 28(7), 621-628.

Boeykens, S.P., Piol M.N., Samudio Legal, L., Saralegui, A.B., Vázquez, C. (2017) Eutrophication decrease: Phosphate adsorption processes in presence of nitrates. Journal of Environmental Management, 203(3), $888-895$.

Eilola, K., Gustafsson, B.G., Kuznetsov, I., Meier, H.E.M., Neumann, T., Savchuk, O.P. (2011). Evaluation of biogeochemical cycles in an ensemble of three state-of-the-art numerical models of the Baltic Sea. Journal of Marine Systems, 88(2), 267-284.

Eilola, K., Meier, H.M., Almroth, E. (2009). On the dynamics of oxygen, phosphorus and cyanobacteria in the Baltic Sea; a model study. Journal of Marine Systems, 75(1), 163-184.

Ekholm, P., Jaakkola, E., Kiirikki, M., Lahti, K., Lehtoranta, J., Mäkelä, V., Näykki, T., Pietola, L., Tattari, S., Valkama, P., Vesikko, L. (2011). The effect of gypsum on phosphorus losses at the catchment scale. The Finnish Environment, 33, 2011.

Ekholm, P., Valkama, P., Jaakkola, E., Kiirikki, M., Lahti, K., Pietola, L. (2012). Gypsum amendment of soils reduces phosphorus losses in an agricultural catchment. Agricultural and Food Science, 21(3), 279291.

Granger, C.W.J., Newbold, P. (1974). Spurious regressions in econometrics. Journal of Econometrics, 2, 111120.

Granger, C.W.J., Newbold, P. (1977). Forecasting Economic Time Series. New York: Academic Press.

Gustafsson, B.G., Schenk, F., Blenckner, T., Eilola, K., Meier, H.M., Müller-Karulis, B., Neumann, T., Ruoho-Airola, T., Savchuk, O.P., Zorita, E. (2012). Reconstructing the development of Baltic Sea eutrophication 1850-2006. Ambio, 41(6), 534-548.

Håkanson, L., Bryhn, A.C. (2008). Eutrophication in the Baltic Sea: Present situation, nutrient transport processes, remedial strategies. Springer Science \& Business Media.

Håkanson, L., Lindgren, D. (2010). Water transport and water retention in five connected subbasins in the Baltic Sea-simulations using a general mass-balance modeling approach for salt and substances. Journal of Coastal Research, 26(2), 241-264.

Hänninen, J., Vuorinen, I. (2015). Riverine tot-P loading and seawater concentrations in the Baltic Sea during the 1970s to 2000 — transfer function modelling based on the total runoff. Environmental Monitoring and Assessment, 187(6), 343.

HELCOM (2006). Development of tools for assessment of eutrophication in the Baltic Sea, Baltic Sea Environment Proceedings, 104, $64 \mathrm{pp}$.

HELCOM (2009). Eutrophication in the Baltic Sea, an integrated thematic assessment of the effects of nutrient enrichment in the Baltic Sea region. Baltic Sea Environment Proceedings, 115B, 148 pp.

HELCOM (2013). Copenhagen Declaration "Taking Further Action to Implement the Baltic Sea Action Plan - Reaching Good Environmental Status for a healthy Baltic Sea". Adopted 3 October 2013. 
HELCOM (2014). Eutrophication status of the Baltic Sea 2007-2011 - a concise thematic assessment, Baltic Sea Environmental Proceedings, 143, 40 pp.

HELCOM (2015). Guidelines for the annual and periodical compilation and reporting of water borne inputs to the Baltic Sea (PLC-Water).

HELCOM (2017). Baltic Sea Action Plan. Adopted by the HELCOM Ministerial meeting, Krakow, Poland $15^{\text {th }}$ November 2017.

Iho, A., Ahlvik, L., Ekholm, P., Lehtoranta, J., Kortelainen, P. (2017). Optimal Phosphorus Abatement Redefined: Insights from Coupled Element Cycles. Ecological Economics, 137, 13-19.

Iho, A., Laukkanen, M. (2012). Gypsum amendment as a means to reduce agricultural phosphorus loading: an economic appraisal. Agricultural and Food Science, 21(3), 307-324.

Jaakkola, E., Tattari, S., Ekholm, P., Pietola, L., Posch, M., Bärlund, I. (2012). Simulated effects of gypsum amendment on phosphorus losses from agricultural soils. Agricultural and Food Science, 21(3), 292306.

Kuosmanen, N. (2014). Estimating stocks and flows of nitrogen: Application of dynamic nutrient balance model to European agriculture. Ecological Economics, 108, 68-78.

Kuosmanen, N., Kuosmanen, T. (2013). Modeling cumulative effects of nutrient surpluses in agriculture: A dynamic approach to material balance accounting. Ecological Economics, 90, 159-167.

Larsen, H.G. (2008). Scaling the Baltic Sea environment. Geoforum, 39(6), 2000-2008.

Larsson, U., Elmgren, R., Wulff, F. (1985). Eutrophication and the Baltic Sea: Causes and Consequences. Ambio, 14, 9-14.

Phillips, P.C.B. (1986). Understanding spurious regressions in econometrics. Journal of Econometrics, 33, $311-$ 340.

Rahm, L., Danielsson, Å. (2007). Spatial heterogeneity of nutrients in the Baltic Proper, Baltic Sea. Estuarine, Coastal and Shelf Science, 73(1), 268-278.

Ryther, J.H., Dunstan, W.M. (1971). Nitrogen, Phosphorus, and Eutrophication in the Coastal Marine Environment. Science, 171, 1008-1013.

Savchuk, O.P. (2005). Resolving the Baltic Sea into seven subbasins: N and P budgets for 1991-1999. Journal of Marine Systems, 56(1), 1-15.

Savchuk, O.P., Gustafsson, B.G., Müller-Karulis, B. (2012). BALTSEM-A Marine Model for the Decision Support within the Baltic Sea Region. Baltic Nest Institute Technical Report, (7), pp.55.

Savchuk, O.P., Wulff, F. (2007). Modeling the Baltic Sea eutrophication in a decision support system. AMBIO: A Journal of the Human Environment, 36(2), 141-148.

Savchuk, O.P., Wulff, F. (2009). Long-term modeling of large-scale nutrient cycles in the entire Baltic Sea. Hydrobiologia, 629(1), 209-224.

Uusitalo, R., Ylivainio, K., Hyväluoma, J., Rasa, K., Kaseva, J., Nylund, P., Pietola, L., Turtola, E. (2012). The effects of gypsum on the transfer of phosphorus and other nutrients through clay soil monoliths. Agricultural and Food Science, 21(3), 260-278.

Voipio, A. (Ed.) (1981). The Baltic Sea. Elsevier, Amsterdam, 418 pp.

Vollenweider, R. (1971). Scientific fundamentals of the eutrophication of lakes and flowing waters, with particular reference to nitrogen and phosphorous as factors in eutrophication, OECD Technical Report DAS/CSI/68.27, OECD, Paris.

Wasmund, N., Andrushaitis, A., Łysiak-Pastuszak, E., Müller-Karulis, B., Nausch, G., Neumann, T., Ojaveer, H., Olenina, I., Postel, L., Witek, Z. (2001). Trophic status of the south-eastern Baltic Sea: a comparison of coastal and open areas. Estuarine, Coastal and Shelf Science, 53(6), 849-864.

Wulff, F., Rahm, L., Hallin, A.K., Sandberg, J. (2001b). A nutrient budget model of the Baltic Sea. In Wulff, F., Rahm, L., Larsson, P. (Eds.): A systems analysis of the Baltic Sea, 353-372. Springer Berlin Heidelberg.

Wulff, F., Rahm, L., Larsson, P. (Eds.) (2001a). A Systems Analysis of the Baltic Sea. Ecological Studies, Vol. 148. Springer-Verlag, Berlin, 455 pp. 
Appendix 1. Development of nutrient loads to the Baltic Sea from different countries during 1994-2005 according to HELCOM and the DNB method.
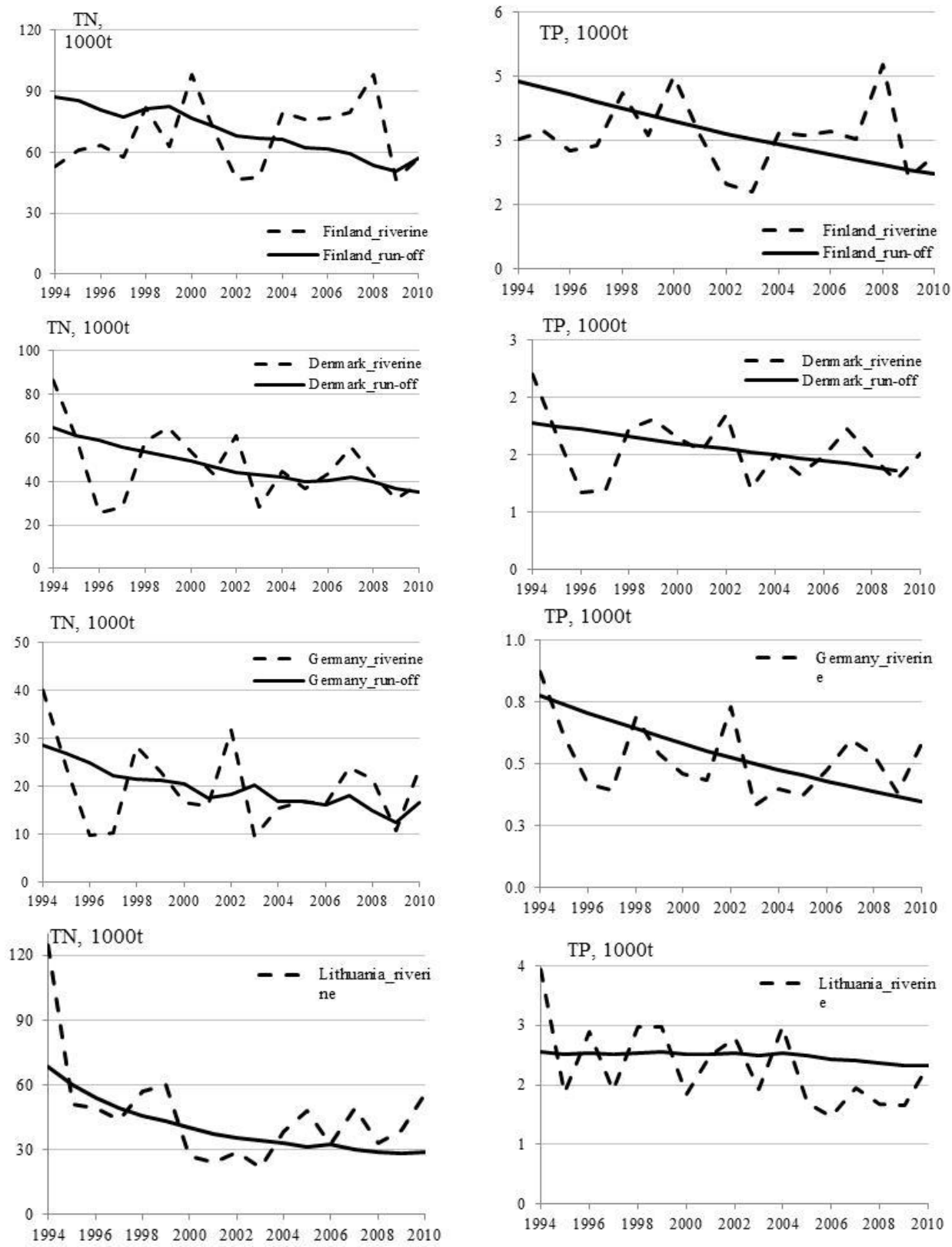

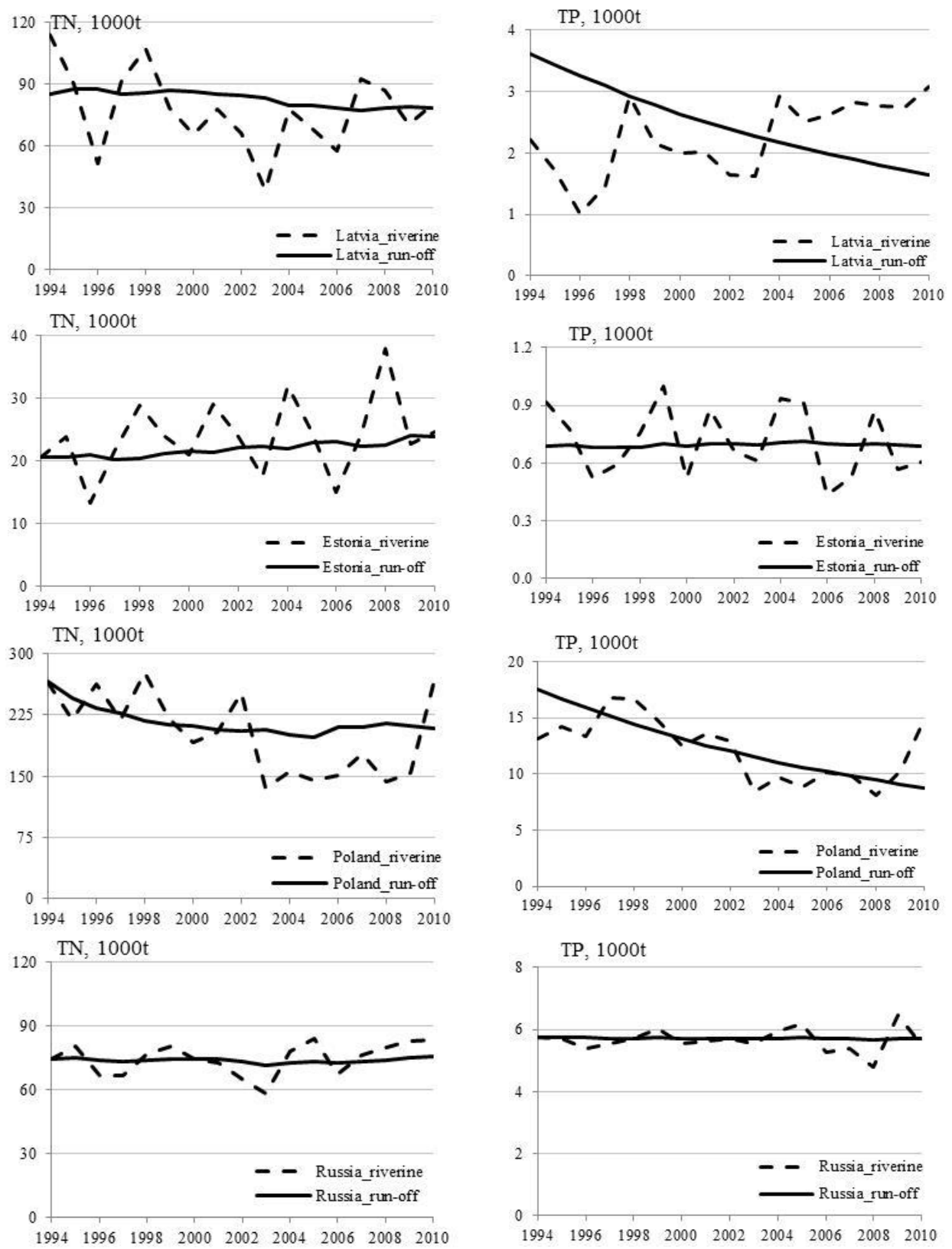
Appendix 2. Development of dissolved inorganic nitrogen (DIN) and dissolved inorganic phosphorus (DIP) concentrations during 1994-2005 according to HELCOM and the DNB method.
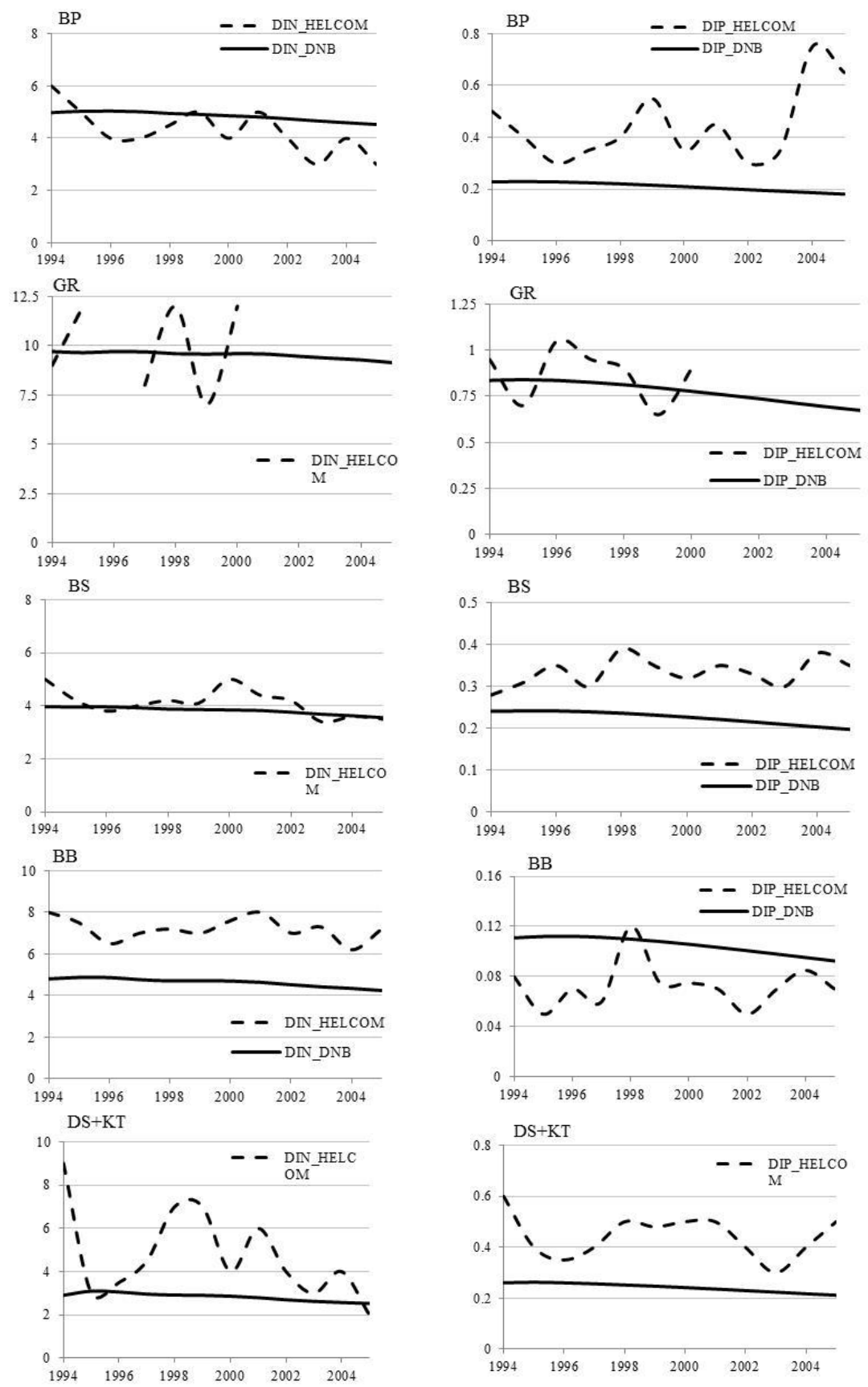